\title{
Lymphangioma of ovary: a case report and review of literature
}

\author{
Sasmita Panda, Sashibhusan Dash, Ashok Kumar Padhy, Asaranti Kar \\ Corresponding author: Dr. Sashibhusan Dash, Senior Reseach Fellow, Department of Pathology, \\ Acharya Harihar Post-Graduate Institute of Cancer, Cuttack, Odisha, India; \\ Email : sashibiotech@gmail.com
}

Distributed under Attribution-Non Commercial - Share Alike 4.0 International (CC BY-NC-SA 4.0)

\section{$\underline{\text { ABSTRACT }}$}

Ovarian lymphangioma is an extremely rare tumor. To date, in PubMed indexed article review, only 23 cases of ovarian lymphangioma were identified. The etiology is not fully understood after its first description. In this research paper, we present an ovarian lymphangioma in a 46 year old Indian woman.

Keywords: Lymphangioma, ovary, histopathology.

Lymphangioma is a congenital malformation which is characterized by proliferation of lymphatic vessel. ${ }^{1}$ The etiology and true occurrence of this tumor is not fully understood. Despite the most common site being head and neck region, it is found to be rare in other anatomical site. ${ }^{2}$ Lymphangioma of ovary is an extremely rare tumor. ${ }^{1}$ To date, in Pub Med indexed article, only 23 cases of ovarian lymphangioma were reported. After its first description, the etiology, clinical presentation and management is still under debate.

Case

A 46 year old Indian woman presented with abdominal pain, altered bowel habits for duration of two weeks. Her physical examination showed no visible lump or swelling. She had no history of trauma, cancer, or radiation exposure.

Ultrasonography of abdomen and pelvis revealed a solid mass, measuring $6 \times 5 \mathrm{~cm}$ which had heterogeneous echotexture with solid and cystic area in right ovary. On the left adnexal area, no significant mass was detected. The uterus and cervix were unremarkable. In the para-aortic and pelvic areas, no lymphadenopathy was noted. Patient did not present with gross ascites, obstruction of small or large intestines. Contrast enhanced computed tomography was suggestive of a right ovarian mass. Ancillary serum tumor markers such as CA125, carcinoembryonic antigen, lactate dehydrogenase and beta human chorionic gonadotropin range were within normal limit.

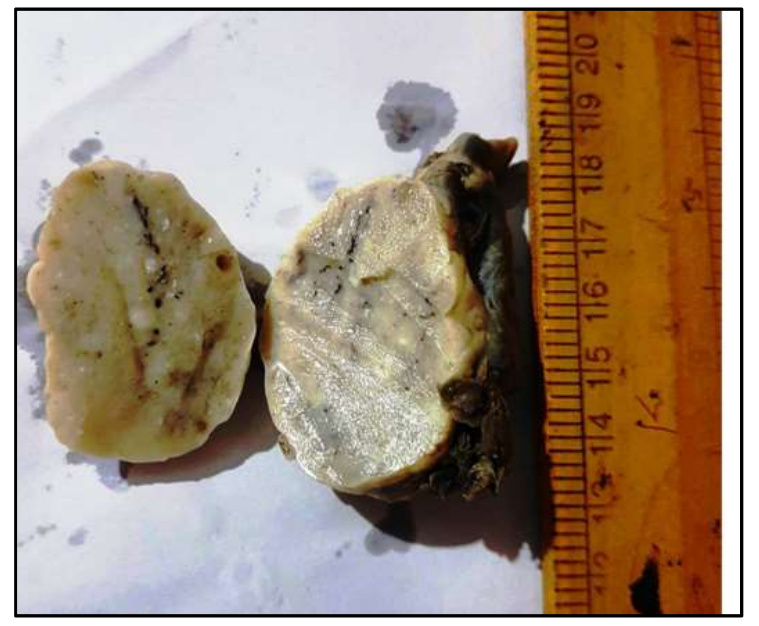

Figure 1: Gross photograph of cut surface showing oval, soft, smooth surface, solid white mass $\mathrm{m} .6 \times 4 \times 4 \mathrm{~cm}$ size.

Grossly, the tumor was oval, $6 \times 4 \times 4 \mathrm{~cm}$ size and smooth surface. Cut section shown soft, solid brownishwhite mass (figure 1). Histopathology sections revealed

Received: $23^{\text {rd }}$ January 2021, Peer review completed: $4^{\text {th }}$ May 2021, Accepted: $7^{\text {th }}$ June 2021.

Panda S, Dash S, Padhy AK, Kar A. Lymphangioma of ovary: a case report and review of literature. The New Indian Journal of OBGYN. 2022; 8(2): 327 - 30. 
dilated cystic spaces lined by flattened endothelial cells containing only lymphocytes and eosinophils (H\&E stain). Thus the diagnosis was given as an ovarian lymphangioma (figure 2). Further to discriminate such case from other pathology, special stains such as (PAS and Alcian blue) and immunohistochemical markers such as CD-34, CD 31 were done. The PAS and Alcian blue stain showed negative while CD-31 and CD-34 showed immunoreactive.

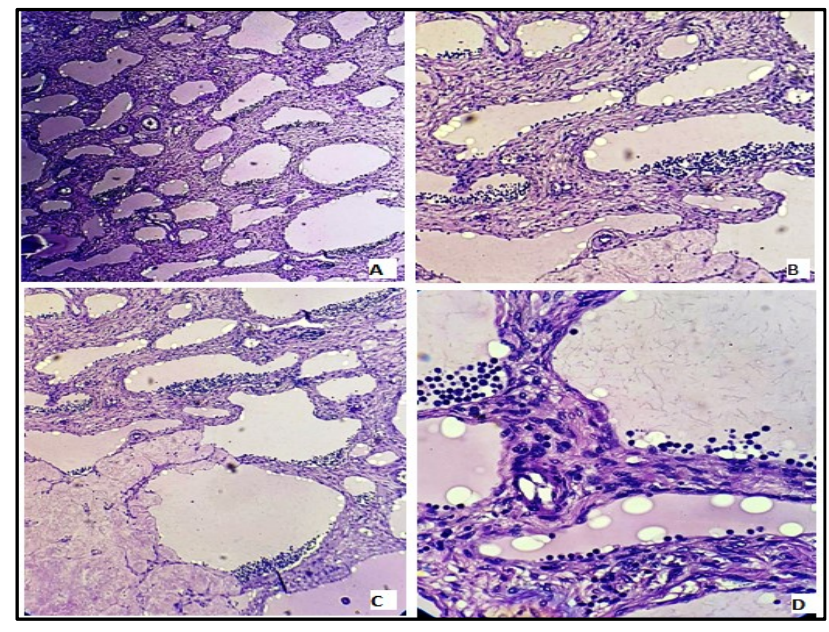

Figure 2(a,b,c,d): Histopathology section showing dilated cystic spaces lined by flattened endothelial cells containing only lymphocytes and eosinophilic material.

Finally the disease was confirmed as ovarian lymphangioma. Subsequently the patient was under follow up. The prognosis was good for six months with clinical and ultrasound monitoring.

\section{Discussion}

Lymphangiomas are tumor of the lymphatic system comprised of multiple cystic spaces lined by endothelium. They can be classified as capillary, cystic, or cavernous. ${ }^{3}$ Pathogenesis and occurrence of lymphangioma is uncertain and matter of discussion. ${ }^{4}$ In children, it more commonly arises in the head, neck, and axilla but in adults, it is most commonly found in superficial cutaneous or intra-abdominal area. ${ }^{4}$ In adult, the etiology is less understood, some authors suggest its origin by proliferation of lymphoid nests after inflammation, fibrosis, or genetic predisposition, end result of mechanical pressure, trauma, degeneration of lymph nodes, and disorders of the lymphatic vasculature. ${ }^{3}$ Localization of lymphangioma in the pelvic region is uncommon among which ovary is found to be extremely rare. $^{3}$
In a study report, lymphatic drainage disorder was found to be underlying cause for ovarian lymphangioma who had chronic follicular salpingitis. ${ }^{5}$ In another case report, radiation exposure due to Willims tumor in a child patient was held responsible. ${ }^{6}$ Akyildiz et al reported a case of ovarian lymphangioma in menopausal period and he found deteriotion of lymphatic circulation due to $35 \mathrm{~cm}$ diameter leiomyoma. $^{7}$ In our case, there was no history of precipitating trauma, infection, or exposure to radiation, no previous surgery or adhesions. The lack of evidence of reactive process suggests a neoplastic cause.

Lymphangioma of ovary usually seen in adult women, but it rarely occur in children. ${ }^{8}$ In published literature, the age of ovarian lymphangiomas ranged from 33 weeks of gestation to 75 years, among which the majority of cases were identified in the reproductive age group.

It was also observed that the majority of ovarian lymphangiomas are slow-growing tumors that remain asymptomatic for a long time, with the tumor being identified incidentally during histopathological examination after excision.?

As with other adnexal masses, pelvic ultrasonography is the preferred imaging method. ${ }^{7}$ Computed tomography or magnetic resonance imaging may add important preoperative information about anatomical relationships with other structures, differentiate benign from malignant and chylous fluid from blood and pus. ${ }^{9}$

In some cases determinants of clinical manifestations are the size and position of lymphangiomas, which can range from asymptomatic to acute onset of severe pain. The most common symptoms of intra-abdominal and pelvic lymphangioma are abdominal pain and distension. Certain indications such as signs of compression, collapse, secondary infection, volvulus, or bowel obstruction may be noticed. ${ }^{10}$ In some ovarian lymphangioma cases, menstrual irregularity was identified as posing complaints. ${ }^{11,12}$

Lymphangioma of the ovary is usually unilateral, case with bilateral lymphangioma has been reported very rarely in literature. ${ }^{13}$ However, very unusual clinical presentation of ovarian lymphangioma was documented even in literature. ${ }^{5}$ In a study report, patient presented with bilateral cystic lymphangioma of ovary along with chylous ascites and chyluria. ${ }^{14}$ Most often the ovarian lymphangioma is located on the surface of the ovary or in the parenchyma and occasionally grows large and causes mass effect and compression of adjacent organs. In a report very big i.e. $40 \mathrm{~cm} \times 15 \mathrm{~cm} \times 29 \mathrm{~cm}$ ovarian lymphangioma was reported in a 16 year old female patient. ${ }^{15}$ Most of the cases, it 
initially creates confusion with malignant ovarian mass that often contributes to extensive surgery. It is therefore very necessary to discriminate against malignant tumors, in order to prevent radical surgery or over treatment.

Histological differential diagnosis of ovarian lymphangioma includes hemangioma, teratoma with a prominent vascular component, secondary lymph channel dilation, and adenomatoid tumor. ${ }^{16}$ As adenomatoid tumor and hemangioma are the main differential diagnosis for ovarian lymphangioma, the presence of thin-walled vascular spaces lined by flat endothelial cells, with pale eosinophilic homogeneous material within the vascular channels, helps to distinguish lymphangioma from hemangioma. ${ }^{17}$ In some cases, special stain (PAS and Alcian blue) helps to distinguish adenomatoid tumor from lymphangioma as adenomatoid tumor stains positively with PAS and Alcian blue whereas lymphangiomas do not stain. ${ }^{16}$

Usually the behavior of ovarian lymphangioma is benign but few cases have recurred and occasional cases have shown transformation to a malignancy. Rice et al ${ }^{18}$ reported a histological benign laparotomy - resected lymphangioma with contra-lateral ovarian involvement, liver metastasis and diffuse intraperitoneal dissemination 6 months after surgery. In another report, Aristizabal et al ${ }^{19}$ identified the recurrence of a benign lymphangioma that appears diffusely in the peritoneal cavity within 2 years of open rescue. So complete clear margin and prolonged follow-up with pelvic examination and gynecological sonography is mandatory every 3 months up to at least 2 years.

The ovarian lymphangioma is very rare. The chosen treatment is surgical and is a complete resection of the lesion. Although most of the time they are benign in nature, wide excision with a clear margin and regular follow-up is compulsory.

\section{Conflict of interest: None. Disclaimer: Nil.}

\section{References}

1. Gonen KA, Abali R, Oznur M, Erdogan C. Lymphangioma: surrounding the ovarian vein and ovary. BMJ Case Rep. 2013; 2013: bcr2013200020.

2. Pani E, Martin A, Buccoliero A, Ghionzoli M, Messineo A. Giant Ovarian Lymphangioma: Case Report and Review of the Literature. Fetal Pediatr Pathol. 2018; 37: 263-69.

3. Naik SA. Rare Case of Ovarian Cystic Lymphangioma Managed at Laparoscopy. J Gynecol Endosc Surg. 2011; 2: $97-100$.
4. Rieker RJ, Quentmeier A, Weiss C, Kretzschmar U, Amann K, Mechtersheimer G, et al. Cystic lymphangioma of the small-bowel mesentery: Case report and a review of the literature. Pathol Oncol Res. 2000; 6:146 - 8.

5. Iwasa T, Tani A, Miyatani Y, Bekku S, Yamashita M, Nakanishi K, et al. Lymphangioma of the ovary accompanied by chylous ascites. J Obstet Gynaecol Res. 2009; 35: 812-15.

6. Heinig J, Beckmann V, Bialas $\mathrm{T}$, Diallo $\mathrm{R}$. Lymphangioma of the ovary after radiation due to Wilms' tumor in the childhood. Eur J Obstet Gynecol Reprod Biol. 2002 Jul 10; 103:191- 4.

7. Akyildiz EU, Peker D, Ilvan S, et al. Lymphangioma of the ovary: a case report and review of the literature. J BUON. 2006; 2013: 91-3.

8. Jain D, Saroha V, Singh M. Lymphangioma of the ovary. J Obstet Gynaecol. 2009; 29: 260-1.

9. Karkera PJ, Sandlas GR, Ranjan RR, Kesan K, Gupta AR, Gupta RK, et al. Intra-abdominal cystic lymphangiomas in children: A Case Series. Archives of International Surgery. 2012; 2: 91-5.

10. Yildiz C, Karadayi K, Sarkis C, Cetin A. Huge cystic lymphangioma mimicking ovarian malignancy: a case report. Turk J Gastroenterol. 2011; 22: 344-46.

11. Joo HJ, Lee TJ, Lee SH, Lee EJ. Lymphangioma Arising From the Ovary. Lymphology. 2016; 49: 21- 6.

12. Siddall RS, Clinton WR. Lymphangioma of the ovary. American Journal of Obstetrics and Gynecology.1937; 34:306-10.

13. Pillai S, O’Brien D, Stewart CJR. Bilateral ovarian lymphangioma (lymphangioleiomyoma). Int J Gyneacol Pathol. 2013; 32:171-75.

14. Nerune SM, Arakeri SU, Patil VL, Mulay HD. Bilateral Cystic Lymphangioma of Ovary Associated with Chylous Ascites. J Clin Diagn Res. 2015; 9: ED18ED19.

15. Radhouane A, Mayada S, Khaled N. Lymphangioma of the ovary: etiology and management. Eur J Obstet Gynecol Reprod Biol. 2016; 203: 342-3.

16. Bavikar RR, Tampi C. Lymphangioma of Ovary. Bombay Hosp J. 2011; 53: 89-91.

17. Ahluwalia J, Girish V, Saha S, Dey P. Lymphangioma of the ovary. Acta Obstet Gynecol Scand. 2000 Oct; 79(10):894-5.

18. Rice M, Pearson B, Treadwell WB. Malignant lymphangioma of the ovary. Am J Obstet Gynecol. 1943; 45: 884-8. 
The New Indian Journal of OBGYN. 2021 (January-June);8(2)

19. Aristizabal SA, Galindo JH, Davis JR, Boone ML. Lymphangiomas involving the ovary. Report of a case and review of the literature. Lymphology. 1977; 10:219-23.

Sasmita Panda ${ }^{1}$, Sashibhusan Dash ${ }^{2}$, Ashok Kumar Padhy ${ }^{3}$, Asaranti Kar ${ }^{4}$
${ }^{1}$ Associate professor, Department of Pathology, Acharya Harihar Post-Graduate Institute of Cancer, Cuttack, Odisha, India; ${ }^{2}$ Senior Reseach Fellow, Department of Pathology, Acharya Harihar PostGraduate Institute of Cancer, Cuttack, Odisha, India; ${ }^{3}$ Assistant Professor, Department of Gynecooncology, Acharya Harihar Post-Graduate Institute of Cancer, Cuttack, Odisha, India; ${ }^{4}$ Department of Pathology, SCB Medical College and Hospital, Odisha, India. 